\title{
Regulation of Immunoglobulin (Ig)E Synthesis in the Hyper-IgE Syndrome
}

\author{
Donata Vercelli, * Haifa H. Jabara, " Charlotte Cunningham-Rundles, „ John S. Abrams, 'David B. Lewis," \\ Jeff Meyer,' Lynda C. Schneider," Donald Y. M. Leung," and Raif S. Geha* \\ *Division of Immunology, The Children's Hospital, and the Department of Pediatrics, Harvard Medical School, Boston, Massachusetts \\ 02115; the ${ }^{\ddagger}$ Departments of Medicine and Pediatrics, Mount Sinai Hospital, New York 10029; the $\S$ Department of Molecular Biology, \\ DNAX Research Institute of Cellular and Molecular Biology, Palo Alto, California 94304; the "Division of Infectious Disease, \\ Department of Pediatrics, and Children's Hospital and Medical Center, University of Washington, Seattle, \\ Washington 98105; and'Immunex Corporation, Seattle, Washington 98101
}

\begin{abstract}
The hyper-IgE (HIE) syndrome is characterized by high IgE serum levels, chronic dermatitis, and recurrent infections. The mechanisms responsible for hyperproduction of IgE in HIE patients are presently unknown. We investigated whether spontaneous in vitro IgE synthesis by PBMC from seven HIE patients was sensitive to signals (cell adhesion, $T / B$ cell cognate interaction and lymphokines: IL-4, IL-6, and IFN- $\gamma$ ) known to regulate IgE induction in normals. Our results show that, unlike IL-4 dependent IgE synthesis induced in normals, spontaneous IgE production by PBMC from HIE patients was not blocked by monoclonal antibodies to CD2, CD4, CD3, and MHC class II antigens. Furthermore, antibodies to $\mathrm{IL}-4$ and IL-6 did not significantly suppress IgE production. IFN- $\gamma$ had no significant effects on spontaneous in vitro IgE synthesis. To test whether an imbalance in lymphokine production might underlie hyperproduction of IgE in HIE patients, mitogen-induced secretion of IL- 4 and IFN- $\gamma$ by PBMC was assessed. No significant difference was detected between HIE patients and normal controls. Thus, ongoing IgE synthesis in the HIE syndrome is largely independent of cell-cell interactions and endogenous lymphokines, and is due to a terminally differentiated B cell population, no longer sensitive to regulatory signals. (J. Clin. Invest. 1990. 85:1666-1671.) interleukin 4 • interleukin $6 \cdot$ interferon- $\gamma \cdot B$ cell differentiation $\cdot$ cell-cell interactions
\end{abstract}

\section{Introduction}

The hyper-IgE (HIE) ${ }^{1}$ syndrome is a complex disorder characterized by high levels of serum IgE, chronic dermatitis and recurrent serious infections (1). The etiology of the HIE syndrome is unknown. There is evidence to suggest that HIE patients have $T$ cell defects, which include impaired in vivo and in vitro $\mathrm{T}$ cell-mediated responses to specific antigens and

Address reprint requests to Dr. Vercelli, Division of Immunology, The Children's Hospital, 300 Longwood Avenue, Boston, MA 02115.

Received for publication 5 July 1989 and in revised form 11 December 1989.

1. Abbreviations used in this paper: EIA, enzyme immunoassay; HIE, hyper-IgE; HS, horse serum; TCR, T cell receptor.

J. Clin. Invest.

(c) The American Society for Clinical Investigation, Inc. 0021-9738/90/05/1666/06 \$2.00

Volume 85, May 1990, 1666-1671 defective antibody responses, particularly to polysaccharides (reviewed in 2,3). The mechanisms responsible for increased IgE production in the HIE syndrome are unknown.

The regulation of IgE synthesis in man has been extensively investigated in recent years. We have shown that the induction of IgE synthesis by normal human B cells requires two signals: the $T$ cell-derived lymphokine IL- 4 and cognate interaction between the $T$ cell receptor (TCR)/CD3 complex on $\mathrm{CD}^{+} \mathrm{T}$ cells and MHC class II antigens on B cells (4). IL-4-dependent IgE production is amplified by lymphokines, i.e., IL-5 and IL-6 $(5,6)$. IFN- $\gamma$ has also been implicated in the regulation of IgE synthesis, as an antagonist to IL-4 (7). Recombinant ( $r$ ) IFN- $\gamma$ inhibits IgE synthesis induced by IL-4 (8, 9); furthermore, T cell clone supernatants containing IL-4 and IFN- $\gamma$ in high concentrations induced IgE production only when anti-IFN- $\gamma$ antibodies were added (10). The mechanisms of action and the cellular targets of IFN- $\gamma$ are, however, still controversial (11).

In this paper, we have investigated the role played by cellular interactions and lymphokines in the regulation of spontaneous IgE synthesis by PBMC from patients with the HIE syndrome. Our data indicate that spontaneous in vitro IgE synthesis in the HIE syndrome is largely independent of endogenous lymphokines (IL-4, IL-6) and T/B cell cognate interactions, and is likely to be due to a terminally differentiated, autonomous B cell population.

\section{Methods}

Patients. Seven children were studied, in whom the HIE syndrome was diagnosed according to the criteria defined by Buckley and Becker (1). All children had a history of chronic dermatitis and recurrent infections, and elevated levels of serum IgE. Clinical characteristics of most of the patients included in this study have been previously described in detail $(2,3)$. Consent was obtained from all subjects or from their parents before obtaining blood for these studies.

Interleukins and antibodies. Human rIL-4 was used in a purified form (sp act: $1.2 \times 10^{7} \mathrm{U} / \mathrm{mg}$ ). Human rIL-6 (specific activity: $5 \times 10^{6}$ $\mathrm{U} / \mathrm{mg}$ ) and a neutralizing polyclonal goat IgG anti-IL-6 antibody were a kind gift of T. Kishimoto and T. Hirano (Osaka University, Japan). rIFN- $\gamma$ (sp act: $2.02 \times 10^{7} \mathrm{U} / \mathrm{mg}$ ) was kindly provided by Genentech (San Francisco, CA). A polyclonal rabbit antibody to IL-4 was a kind gift of Dr. J. de Vries (DNAX, Palo Alto, CA). Anti-HLA-DR (clone L243, IgG2a specific for a nonpolymorphic HLA-DR epitope), antiLeu 4 (IgG1 anti-CD3), anti-Leu 3a (IgG1 anti-CD4), anti-Leu 2a (IgG1 anti-CD8), anti-Leu 5b (IgG2 anti-CD2) monoclonal antibodies (MAbs), as well as the appropriate isotype controls, were obtained from Becton Dickinson (Mountain View, CA).

Cell cultures. PBMC were isolated from heparinized venous blood by density gradient centrifugation on Ficoll-Hypaque (Pharmacia Fine Chemicals, Piscataway, NJ), washed three times in Hanks' balanced 
salt solution (Microbiological Associates, Bethesda, MD) and resuspended at $1.5 \times 10^{6}$ cells $/ \mathrm{ml}$ in RPMI $1640-10 \%$ heat-inactivated FCS (Hyclone, Sterile Systems, Inc., Logan, UT) supplemented with $2 \mathrm{mM}$ L-glutamine, $50 \mu \mathrm{g} / \mathrm{ml}$ streptomycin, and $100 \mathrm{U} / \mathrm{ml}$ penicillin (complete medium). Cells were cultured at $37^{\circ} \mathrm{C}$ in a $5 \% \mathrm{CO}_{2}$ humidified atmosphere. Control cultures for the evaluation of preformed IgE were set up in the presence of cycloheximide $(100 \mu \mathrm{g} / \mathrm{ml})$. Lymphokines and antibodies were added as indicated for each experiment in Results. After 9-10 d, culture supernatants were harvested and assessed by RIA for their IgE content. Net IgE synthesis was evaluated by subtracting IgE concentrations found in cycloheximide-treated cultures from IgE values found in untreated cultures.

RIA for $I g E$. The assay was performed in flexible flat bottom microtiter plates (Cooke Laboratory Products, Alexandria, VA) at room temperature as previously described (12). The wells were coated with $0.1 \mathrm{ml}$ of a 1:1 mixture of purified anti-Fc $\epsilon$ MAbs (7.12 and 4.15, a kind gift of A. Saxon, University of California, Los Angeles), $2 \mu \mathrm{g} / \mathrm{ml}$ in carbonate-bicarbonate buffer, $\mathrm{pH}$ 9.6. After a 16-h incubation, the wells were washed, blocked with PBS-10\% horse serum (HS) for $2 \mathrm{~h}$ and subsequently washed three times with PBS- $1 \%$ HS. $0.1 \mathrm{ml}$ of culture supernatant or different dilutions of IgE standard (Pharmacia Fine Chemicals) were then added to the wells in triplicate and incubated for $16 \mathrm{~h}$ in a humidified chamber. The wells were then washed twice with PBS- $1 \%$ HS containing $0.5 \%$ Tween 20 , twice with PBS- $1 \%$ $\mathrm{HS}$, and finally incubated with $0.1 \mathrm{ml}$ of Phadebas RAST ${ }^{125} \mathrm{I}$-antihuman IgE (ND) (Pharmacia) for $6 \mathrm{~h}$. The wells were then washed three times with PBS-1\% HS, eight times under running distilled water, cut out, and counted in a gamma spectrometer (Tracor Analytic Co., Elk Grove Village, IL). The concentrations of IgE in the supernatants were read from the standard curve. The lower limit of sensitivity of this assay is $150 \mathrm{pg} / \mathrm{ml}$. This assay was validated in a recent multicenter collaborative assessment of the variability of IgE measurement in cell culture supernatants (13).

Preparation of PBMC supernatants. PBMC from HIE patients and age-matched normal controls were suspended at $5 \times 10^{6} \mathrm{cells} / \mathrm{ml}$ in serum-free AIM-V medium (Gibco Laboratories, Grand Island, NY) for IL-4 assay (14), or at $1 \times 10^{6} \mathrm{cells} / \mathrm{ml}$ in complete medium for IFN- $\gamma$ and IL-2 determinations. Cells were stimulated with Con A (Calbiochem-Behring Co., La Jolla, CA; $10 \mu \mathrm{g} / \mathrm{ml}$ ) or phorbol myristate acetate $(50 \mathrm{ng} / \mathrm{ml}$ PMA; Sigma Chemical Co., St. Louis, MO) $+0.5 \mu \mathrm{M}$ ionomycin (Calbiochem-Behring). After $24 \mathrm{~h}$ (for IL-4 assays) and $48 \mathrm{~h}$ (for IFN- $\gamma$ and IL-2 assays), the supernatants were harvested and stored at $-80^{\circ} \mathrm{C}$.

Assays for lymphokine production. IL-4 concentrations in PBMC culture supernatants were determined by enzyme immunoassay (EIA). Briefly, 96-well polystyrene plates (high binding grade; Corning, Palo Alto, CA) were coated overnight at $4^{\circ} \mathrm{C}$ with a purified murine $\mathrm{MAb}$ specific for human rIL-4 (rhu IL-4M1, $5 \mu \mathrm{g} / \mathrm{ml}$ in PBS). All subsequent steps were performed at room temperature and PBS- $0.05 \%$ Tween 20 was used for washing. The antibody solution was removed, and the wells were washed and blocked with non-fat dry milk (Carnation, Los Angeles, CA 5\% in PBS) for $1 \mathrm{~h}$. After washing, samples or human rIL-4 standards diluted in PBS-10\% goat serum were added to the wells for $1 \mathrm{~h}$. The plates were subsequently washed, incubated for $1 \mathrm{~h}$ with a rabbit anti-human rIL-4 antiserum (14) diluted in PBS-10\% goat serum, washed again, and finally incubated for $1 \mathrm{~h}$ with goat anti-rabbit horseradish peroxidase (EIA grade; Bio-Rad Laboratories, Richmond, CA) diluted in PBS-5\% non-fat dry milk. After washing, the plates were developed with a $1: 1(\mathrm{vol} / \mathrm{vol})$ mixture of peroxidase and tetramethylbenzidine substrate solutions (Kirkegaard \& Perry Laboratories, Inc., Gaithersburg, $M D)$. $\mathrm{OD}_{650}$ was determined after $15-30$ min of incubation. This assay has a lower limit of sensitivity of $\approx 15$ $\mathrm{pg} / \mathrm{ml}$, and does not cross-react with human $\operatorname{rIFN}-\gamma, \mathrm{IL}-1 \alpha, \mathrm{IL}-1 \beta$, IL-2, IL-3, IL-5, IL-6, IL-7, G-CSF, GM-CSF, and CSF-1 at concentrations of $1 \mu \mathrm{g} / \mathrm{ml}$.

IFN- $\gamma$ concentrations were determined using a specific, commercially available RIA (Centocor, Malvern, PA), whose lower limit of sensitivity is $0.1 \mathrm{U} / \mathrm{ml}$. IL-2 concentrations in the supernatants were determined by a bioassay (kindly performed by Dr. R. Miller, Boston University, Boston, MA) which measured the proliferation of murine CTLL cells in response to the supernatants.

Statistical analysis. Data were analyzed by the $t$ test for paired or independent samples.

\section{Results}

Clinical findings and serum IgE levels. The clinical characteristics of the seven patients with the HIE syndrome included in this study are shown in Table I. Their age ranged from 8 to 30 $\mathrm{yr}$, and they comprised four females and three males. Serum IgE levels at presentation were markedly elevated in all the patients.

Role of cell-cell interactions in spontaneous IgE synthesis by PBMC from HIE patients. We have previously shown that MAbs to the cell adhesion molecules CD2 and CD4, but not CD8, inhibit $\mathrm{T}$ cell-dependent induction of human IgE synthesis by rIL-4 (4). To investigate whether spontaneous in vitro IgE synthesis in the HIE syndrome is regulated by similar signals, we assessed the effect of these MAbs on in vitro IgE production by PBMC from HIE patients. Table II shows that addition of MAbs to CD2 and CD4, at concentrations known to inhibit strongly, and often completely, IL-4 dependent induction of IgE synthesis by normal PBMC (4), had no significant effect on spontaneous IgE synthesis by PBMC from HIE patients. As expected, addition of anti-CD8 MAb did not affect in vitro IgE synthesis. Thus, cell adhesion is not required for spontaneous IgE production in HIE patients.

Our previous experiments had shown that IL-4-dependent induction of IgE synthesis by normal PBMC was consistently and completely blocked by both anti-CD3 and anti-MHC class II MAbs, because these MAbs inhibit cognate interaction between the TCR/CD3 complex and MHC class II antigens (4). By contrast, Table III shows that anti-MHC class II and antiCD3 MAbs, at concentrations which abolished IL-4-dependent IgE synthesis by normal PBMC (4), did not significantly affect spontaneous IgE synthesis by PBMC from HIE patients. The finding that anti-CD3 and anti-MHC class II MAb did not inhibit spontaneous IgE production suggests that ongoing IgE synthesis by PBMC from HIE patients does not require cognate $T / B$ cell interactions.

Role of lymphokines in spontaneous IgE synthesis by PBMC from HIE patients. We next asked whether spontaneous IgE synthesis in HIE patients is dependent on endogenous IL-4 or IL-6. Table IV shows that no significant inhibition of spontaneous IgE synthesis was observed with an anti-IL-4 antibody that completely blocked IgE induction by IL-4-producing $\mathrm{T}$ cell clones $(4,8)$, or with an anti-IL-6 antibody which inhibited IL-4-dependent IgE production by normal B cells (6). Thus, a substantial synthesis of IgE can occur in HIE patients without the contribution of endogenous IL-4 and IL-6.

We then investigated whether addition of exogenous rIFN- $\gamma$ might modulate spontaneous IgE production by PBMC from HIE patients. As shown in Table V, rIFN- $\gamma$ had no significant effect on baseline IgE synthesis.

Lymphokine release by PBMC of HIE patients. Although the previous experiments had shown that the sustainment of IgE synthesis in HIE patients is no longer dependent on endogenous lymphokines, the possibility existed that the initiation of 
Table I. Clinical Findings in Patients with the Hyper-IgE Syndrome

\begin{tabular}{|c|c|c|c|c|}
\hline Patient & Age/Sex & Serum IgE* & Infections & Other features \\
\hline 1 & $21 / \mathrm{F}$ & 19,800 & $\begin{array}{l}\text { Staphylococcus: pneumonia, abscesses, cellulitis, osteomyelitis } \\
\text { Candida: meningitis, pneumonia, skin } \\
\text { Pseudomonas: pneumonia } \\
\text { Herpes zoster: skin } \\
\text { Aspergillus: pneumonia }\end{array}$ & $\begin{array}{l}\text { Dermatitis, coarse facies, bone fractures, } \\
\text { allergic rhinitis, keratoconjunctivitis }\end{array}$ \\
\hline 2 & $11 / \mathrm{M}$ & 13,500 & $\begin{array}{l}\text { Staphylococcus: pneumonia, abscesses, osteomyelitis } \\
\text { Candida: esophagitis, skin } \\
\text { Haemophilus: otitis, abscesses }\end{array}$ & Dermatitis, coarse facies, bone fractures \\
\hline 3 & $11 / \mathrm{F}$ & 24,000 & $\begin{array}{l}\text { Staphylococcus: abscesses, sinusitis, pneumonia } \\
\text { Candida: skin, buccal mucosa } \\
\text { Haemophilus: cellulitis } \\
\text { Herpes zoster: skin, eyes }\end{array}$ & $\begin{array}{l}\text { Dermatitis, coarse facies, bone fractures, } \\
\text { allergic rhinitis, keratoconjunctivitis }\end{array}$ \\
\hline 4 & $10 / \mathrm{M}$ & 19,500 & $\begin{array}{l}\text { Staphylococcus: septic arthritis, pneumonia, abscesses, cellulitis } \\
\text { Herpes simplex: skin, eyes }\end{array}$ & $\begin{array}{l}\text { Dermatitis, coarse facies, asthma/ } \\
\text { allergic rhinitis, keratoconjunctivitis }\end{array}$ \\
\hline 5 & $11 / \mathrm{M}$ & 1,950 & $\begin{array}{l}\text { Staphylococcus: abscesses, cellulitis, pneumonia, sinusitis } \\
\text { Candida: skin, buccal mucosa }\end{array}$ & Dermatitis, coarse facies \\
\hline 6 & $8 / \mathrm{F}$ & 32,700 & $\begin{array}{l}\text { Staphylococcus: skin } \\
\text { Haemophilus: pneumonia }\end{array}$ & Dermatitis, coarse facies \\
\hline 7 & $30 / \mathrm{M}$ & 990 & Staphylococcus: skin, knee synovium, brain, lung & Coarse facies, cranial synostosis \\
\hline
\end{tabular}

* At presentation (IU/ml).

the IgE response resulted from an imbalance in the production of lymphokines, particularly IL- 4 and IFN- $\gamma$, which play crucial and antagonistic roles in the regulation of IgE synthesis (reviewed in 15). We therefore investigated the ability of PBMC from HIE patients to secrete IL- 4 and IFN- $\gamma$ upon mitogen stimulation. IL-2 release was also assessed, as a control. As shown in Table VI, lymphokine secretion induced by PMA + ionomycin was not significantly different in HIE patients and age-matched normal controls. Similar results were obtained by assessing lymphokine concentrations in supernatants from Con A-activated PBMC (data not shown). No cor- rection had to be made for the number of $\mathrm{T}$ cells and/or the profile of $T$ cell subsets, because these were essentially normal in our patients (data not shown).

\section{Discussion}

Our results show that the B cells that spontaneously secrete IgE in HIE patients are no longer sensitive to regulatory signals known to modulate IgE induction in normals. Unlike IL-4 dependent IgE synthesis induced in normals $(4,6)$, ongoing in vitro IgE production by PBMC from HIE patients was not

Table II. Disruption of Cell Adhesion Does Not Inhibit Spontaneous In Vitro IgE Synthesis by PBMC from HIE Patients

\begin{tabular}{|c|c|c|c|c|}
\hline \multirow[b]{2}{*}{ Patient } & \multicolumn{4}{|c|}{ Net IgE synthesis $(p g / m l)$} \\
\hline & MAb added: & anti-CD2 & anti-CD4 & anti-CD8 \\
\hline 1 & 13,200 & 8,550 & 12,750 & 10,650 \\
\hline 2 & 4,200 & 5,700 & 3,800 & 3,350 \\
\hline 3 & 8,100 & 11,900 & 11,000 & 9,700 \\
\hline 4 & 9,700 & 15,000 & 20,100 & 20,100 \\
\hline Mean \pm SD & $8,800 \pm 3,733$ & $10,287 \pm 4,036^{*}$ & $11,912 \pm 6,692^{*}$ & $10,950 \pm 6,907^{*}$ \\
\hline
\end{tabular}

Unfractionated PBMC $\left(1.5 \times 10^{6} \mathrm{cells} / \mathrm{ml}\right)$ from HIE patients were cultured in the presence of medium or anti-CD2 (1 $\left.\mu \mathrm{g} / \mathrm{ml}\right)$, anti-CD4 (2.5 $\mu \mathrm{g} / \mathrm{ml})$ and anti-CD8 $(1 \mu \mathrm{g} / \mathrm{ml})$ MAbs. After 9-10 d, culture supernatants were harvested and assessed by RIA for their IgE content. Net IgE synthesis was evaluated by subtracting IgE concentrations found in cycloheximide-treated cultures from IgE values found in untreated cultures. Statistical analysis was performed by the $t$ test for paired samples. ${ }^{*}$ Not significant $(P>0.05)$. 
Table III. Role of T/B Cell Cognate Interactions in Spontaneous In Vitro IgE Synthesis by PBMC from HIE Patients

\begin{tabular}{|c|c|c|c|c|}
\hline \multirow[b]{2}{*}{ Patient } & \multicolumn{4}{|c|}{ Net IgE synthesis $(p g / m l)$} \\
\hline & MAb added: & Nil & $\begin{array}{c}\text { anti-MHC } \\
\text { class II }\end{array}$ & anti-CD3 \\
\hline 1 & & 13,200 & 16,950 & 4,000 \\
\hline 2 & & 4,200 & 6,900 & 1,200 \\
\hline 3 & & 8,100 & 6,200 & 9,900 \\
\hline 4 & & 9,700 & 8,800 & 7,700 \\
\hline Mean \pm SD & & $8,800 \pm 3,733$ & $9,712 \pm 4,948^{*}$ & $5,700 \pm 3,863^{*}$ \\
\hline
\end{tabular}

Unfractionated PBMC $\left(1.5 \times 10^{6}\right.$ cells $\left./ \mathrm{ml}\right)$ from HIE patients were cultured in the presence of medium, anti-CD3 $(0.1 \mu \mathrm{g} / \mathrm{ml})$ or antiMHC class II (HLA-DR: $2.5 \mu \mathrm{g} / \mathrm{ml}$ ) MAbs. After 9-10 d culture supernatants were harvested and assessed by RIA for their IgE content. Net IgE synthesis was evaluated as described in the legend to Table II. Statistical analysis was performed by the $t$ test for paired samples. * Not significant $(P>0.05)$.

significantly blocked by antibodies specific for IL-4, IL-6, CD2, CD4, CD3, or MHC class II antigens. Taken together, these results indicate that spontaneous IgE synthesis in HIE patients is largely independent of endogenous lymphokines, $\mathrm{T} / \mathrm{B}$ cell cognate interaction, or cell adhesion. Ongoing in vitro production of $\mathrm{IgE}$ in the HIE syndrome is derived from an in vivo preactivated $B$ cell population which is terminally differentiated and functionally autonomous. This conclusion is in agreement with previous results from us and others (16-18),

Table IV. Effects of Antibodies to IL-4 and IL-6 on Spontaneous In Vitro IgE Synthesis by PBMC from HIE Patients

\begin{tabular}{ccc}
\hline Patient & \multicolumn{3}{c}{ Net IgE synthesis $(p g / m l)$} \\
\hline & Nil & Anti-IL-4 \\
1 & 13,200 & 12,300 \\
2 & 4,200 & 1,900 \\
3 & 1,300 & 1,625 \\
4 & 5,800 & 2,400 \\
Mean \pm SD & $6,125 \pm 5,071$ & $4,556 \pm 5,172^{*}$
\end{tabular}

\begin{tabular}{|c|c|c|}
\hline & Antibody added: & Anti-IL-6 \\
\hline 1 & 19,000 & 6,600 \\
\hline 2 & 1,300 & 1,200 \\
\hline 3 & 8,100 & 4,450 \\
\hline 4 & 9,700 & 3,100 \\
\hline 6 & 9,600 & 8,060 \\
\hline Mean \pm SD & $9,540 \pm 6,314$ & $4,682 \pm 2,728^{*}$ \\
\hline
\end{tabular}

Unfractionated PBMC $\left(1.5 \times 10^{6}\right.$ cells $\left./ \mathrm{ml}\right)$ from HIE patients were cultured with medium or a polyclonal antibody specific for IL-4 (1:500) or IL-6 $(100 \mu \mathrm{g} / \mathrm{ml})$. After 9-10 d, culture supernatants were harvested and assessed by RIA for their IgE content. Net IgE synthesis was evaluated as described in the legend to Table II. Statistical analysis was performed by the $t$ test for paired samples.

* Not significant $(P>0.05)$ and finds further support in the observation that no significant upregulation of in vitro IgE synthesis by PBMC from HIE patients occurred upon stimulation with rIL-4 or rIL-6 (data not shown). Our results, however, do not rule out the possibility that spontaneous IgE production by B cells from HIE patients may be modulated by cytokines and/or factors other than the ones studied herein, e.g., potentiating factors acting on IgE-bearing B cells $(17,19)$.

The finding that an anti-IL-4 antibody does not significantly inhibit spontaneous in vitro IgE synthesis in HIE patients is not surprising, in view of results recently obtained in vivo in the murine model (20). In the latter, an anti-IL-4 antibody injected late in the course of the IgE response did not block the synthesis of IgE induced by administration of goat anti-mouse IgD antibody, or inoculation of Nippostrongylus brasiliensis. Inhibition was, however, complete when the antiIL-4 antibody was administered in the initial phase of the response. This suggests that IL-4 triggers IgE production by acting at an early, relatively brief, stage.

Our preliminary report, in abstract form (21), of an imbalance in lymphokine production (i.e., increased release of IL-4 and decreased release of IFN- $\gamma$ ) by PBMC from HIE patients was not confirmed in the present study, in which a larger group of patients and normal controls were simultaneously investigated. To induce lymphokine secretion, PBMC from HIE patients were stimulated with Con A or PMA + ionophore. Con A activates T cells through the TCR/CD3 complex (22). HIE patients, however, have defective proliferative responses to specific antigens, which may in turn reflect alterations in TCR/CD3-mediated signaling. In addition to Con A, we therefore used PMA + ionophore, because signaling of $T$ cells by the latter agents bypasses surface receptors and does not require accessory cells (reviewed in [23]). Furthermore, it has recently been shown that stimulation with PMA + ionophore is optimal for the induction of IL-4 and IFN- $\gamma$ mRNA in normal PBMC (14). Regardless of the stimulation protocol, no significant difference in the production of IFN- $\gamma$ and/or IL-4 was detected in HIE patients and normal controls.

These data indicate that no immediate causal relation can be established between increased production of IgE and lymphokine secretion in HIE patients. Hyperproduction of T cellderived IL-4 (absolute, or relative to IFN- $\gamma$ ) may occur, but mainly at a local and/or peripheral level, thus escaping our detection. In this respect, it has been observed that most circulating B cells from patients with hyper-IgE states bear CD23/ FceR2b on their membrane (Kishimoto, T., unpublished observation). This indirectly suggests that IL-4 may be abnormally secreted in HIE patients, because the expression of Fc $\epsilon$ R $2 b$ on B cells is IL-4 dependent (24). IL-4 and other lymphokines now shown to play a role in IgE synthesis may have contributed to the IgE-inducing activity previously detected in supernatants from T cells of HIE patients (25). The frequent finding of eosinophilia in patients with the HIE syndrome (3) also supports this hypothesis, because eosinophil differentiation is induced by IL-5 (26), which is produced by T cell clones concomitantly with IL-4 $(8,15)$.

IL-4 may also be derived from a non-T cell source. It has recently been shown that murine mast cells secrete IL-4 in response to cross-linkage of the high affinity receptor for IgE or to calcium ionophores (27). Should this be demonstrated in humans as well, mast cells would represent a local source of 


\begin{tabular}{ccccc}
\hline & \multicolumn{5}{c}{ Net IgE synthesis $(p g / m l)$} \\
\cline { 2 - 5 } Patient & Stimulant: & Nil & $20 U / m l$ & IFN- $\gamma$ \\
\hline & & & $100 U / m l$ & $500 U / m l$ \\
1 & 19,000 & 8,500 & 8,200 & 9,200 \\
2 & 1,300 & 1,700 & 1,250 & 1,500 \\
3 & 8,100 & 7,300 & 4,800 & 3,800 \\
4 & 5,800 & 9,050 & 4,500 & ND \\
6 & 9,600 & 8,800 & 3,700 & $5,087 \pm 3,256^{*}$ \\
\hline
\end{tabular}

Unfractionated PBMC $\left(1.5 \times 10^{6}\right.$ cells/ml $)$ from HIE patients were cultured with medium or IFN- $\gamma$ at different concentrations. After $9-10 \mathrm{~d}$, culture supernatants were harvested and assessed by RIA for their IgE content. Net IgE synthesis was evaluated as described in the legend to Table II. Statistical analysis was performed by the $t$ test for paired samples. ${ }^{*}$ Not significant $(P>0.05)$.

IL-4, which may provide one of the two signals necessary to activate $B$ cells into IgE secretion (4). The second signal may be provided by polyclonal activators, acting directly on B cells. In this respect, we and others have recently shown that stimulation with rIL-4 and EBV induces IgE synthesis by highly purified normal human B cells (28) (D. Vercelli et al. Manuscript in preparation). Thus, activation of B cells by EBV can replace activation via $T / B$ cell cognate interaction. It is tempting to speculate that hyperproduction of IgE in the HIE syndrome may derive, at least in part, from $\mathrm{T}$ cell-independent mechanisms.

Table VI. Lymphokine Production by PBMC from Patients with the HIE Syndrome

\begin{tabular}{cccc}
\hline & \multicolumn{3}{c}{ Lymphokine secretion } \\
\cline { 2 - 4 } Patient & IL-4 & IFN- & IL-2 \\
\hline & $p g / m l$ & $U / m l$ & $U / m l$ \\
1 & 620 & 1,200 & 1,040 \\
2 & 300 & 740 & 650 \\
3 & 387 & 790 & ND \\
4 & 340 & 1,890 & 630 \\
5 & 100 & 1,480 & 330 \\
6 & $\mathrm{ND}$ & 680 & ND \\
7 & 600 & 2,320 & ND \\
Mean \pm SD: & $391 \pm 195$ & $1,300 \pm 631$ & $662 \pm 291$ \\
Normals: & $724 \pm 672^{*}$ & $966 \pm 562^{*}$ & $673 \pm 480^{*}$ \\
& $(n=11)$ & $(n=18)$ & $(n=5)$ \\
\hline
\end{tabular}

PBMC from HIE patients and age-matched normal controls were suspended at $5 \times 10^{6}$ cells $/ \mathrm{ml}$ in serum-free AIM-V medium for IL-4 assay, or at $1 \times 10^{6}$ cells $/ \mathrm{ml}$ in complete medium for IFN- $\gamma$ and IL-2 determinations. The cells were stimulated with PMA $(50 \mathrm{ng} / \mathrm{ml})$ + ionomycin $(0.5 \mu \mathrm{M})$; after $24-48 \mathrm{~h}$, the supernatants were harvested and stored at $-80^{\circ} \mathrm{C}$. IL- 4 and IFN- $\gamma$ concentrations in PBMC supernatants were determined by EIA and RIA, respectively. IL-2 concentrations were assessed by bioassay. Statistical analysis was performed by the $t$ test for independent samples. ${ }^{*}$ Not significant $(P>0.05)$.

\section{Acknowledgments}

Our work was supported by U. S. Public Health Service grants AI-22058 and AG-04727-07. Dr. Vercelli was the recipient of a Developing Investigator Award from the Asthma \& Allergy Foundation of America.

\section{References}

1. Buckley, R. H., and W. G. Becker. 1978. Abnormalities in the regulation of human IgE synthesis. Immunol. Rev. 41:288-313.

2. Leung, D. Y. M., and R. S. Geha. 1988. Clinical and immunologic aspects of the hyperimmunoglobulin E syndrome. Hematology/ Oncol. Clin. N. Am. 2:81-100.

3. Geha, R. S., and D. Y. M. Leung. 1989. Hyper immunoglobulin E syndrome. Immunodeficiency Rev. 1:155-172.

4. Vercelli, D., H. H. Jabara, K. Arai, and R. S. Geha. 1989. Induction of human IgE synthesis requires interleukin 4 and T/B cell interactions involving the $\mathrm{T}$ cell receptor/CD3 complex and MHC class II antigens. J. Exp. Med. 169:1295-1307.

5. Pene, J., F. Rousset, F. Briere, I. Chretien, J. Wideman, J. Y. Bonnefoy, and J. E. deVries. 1988. Interleukin 5 enhances interleukin-4-induced IgE production by normal human B cells. The role of soluble CD23 antigen. Eur. J. Immunol. 18:929-935.

6. Vercelli, D., H. H. Jabara, K. Arai, T. Yokota, and R. S. Geha. 1989. Endogenous IL-6 plays an obligatory role in IL-4 induced human IgE synthesis. Eur. J. Immunol. 19:1419-1424.

7. Del Prete, G. F., E. Maggi, P. Parronchi, I. Chretien, A. Tiri, D. Macchia, M. Ricci, J. Banchereau, J. deVries, and S. Romagnani. 1988. IL-4 is an essential factor for the IgE synthesis induced in vitro by human T cell clones and their supernatants. J. Immunol. 140:41934198.

8. Jabara, H. H., S. J. Ackerman, D. Vercelli, T. Yokota, K. Arai, J. Abrams, A. M. Dvorak, M. C. Lavigne, J. Banchereau, J. deVries, D. Y. M. Leung, and R. S. Geha. 1988. Induction of interleukin-4 dependent IgE synthesis and interleukin- 5 dependent eosinophil differentiation by supernatants of a human helper T cell clone. J. Clin. Immunol. 8:437-446.

9. Pene, J., F. Rousset, F. Briere, I. Chretien, J. Y. Bonnefoy, H. Spits, T. Yokota, N. Arai, K. Arai, J. Banchereau, and J. deVries. 1988. IgE production by normal human lymphocytes is induced by interleukin 4 and suppressed by interferons $\gamma$ and $\alpha$ and prostaglandin $E_{2}$. Proc. Natl. Acad. Sci. USA. 85:6880-6884.

10. Pene, J., F. Rousset, F. Briere, I. Chretien, X. Paliard, J. Banchereau, H. Spits, and J. E. deVries. 1988. IgE production by normal 
human B cells induced by alloreactive T cell clones is mediated by IL-4 and suppressed by IFN- $\gamma$. J. Immunol. 141:1218-1224.

11. Gordon, J., and G. R. Guy. 1987. The molecules controlling B lymphocytes. Immunol. Today. 8:339-344.

12. Umetsu, D. T., D. Y. M. Leung, R. Siraganian, H. H. Jabara, and R.S. Geha. 1985. Differential requirements of B cells from normal and allergic subjects for the induction of IgE synthesis by an alloreactive T cell clone. J. Exp. Med. 162:202-214.

13. Helm, R. M., R. H. Buckley, N. F. Adkinson, D. L. Squillace, G. J. Gleich, and J. W. Yunginger. 1986. Variability of IgE protein measurement in cell-culture supernatants: results from a multicenter collaborative study. J. Allergy Clin. Immunol. 77:880-890.

14. Lewis, D. B., K. S. Prickett, A. Larsen, K. Grabstein, M. Weaver, and C. B. Wilson. 1988. Restricted production of interleukin 4 by activated human T cells. Proc. Natl. Acad. Sci. USA. 85:97439747.

15. Vercelli, D., and R. S. Geha. 1989. Regulation of IgE synthesis in man. J. Clin. Immunol. 9:75-83.

16. Ricci, M., G. F. Del Prete, E. Maggi, A. Lanzavecchia, P. G. Sala, and S. Romagnani. 1985. In vitro synthesis of human IgE: reappraisal of a 5-year study. Int. Arch. Allergy Appl. Immunol. 77:32-37.

17. Leung, D. Y. M., M. C. Young, N. Wood, and R. S. Geha. 1986. Induction of IgE synthesis in normal human B cells. Sequential requirements for activation by an alloreactive $T$ cell clone and IgE-potentiating factors. J. Exp. Med. 163:713-723.

18. Leung, D. Y. M., and R. S. Geha. 1986. Control of IgE synthesis in man. J. Clin. Immunol. 6:273-283.

19. Young, M. C., D. Y. M. Leung, and R. S. Geha. 1984. Production of IgE-potentiating factor in man by $\mathrm{T}$ cell lines bearing Fc receptors for IgE. Eur. J. Immunol. 14:871-878.

20. Finkelman, F. D., J. Holmes, J. F. Urban, W. E. Paul, and I. M. Katona. 1989. T cell help requirements for the generation of an in vivo
IgE response: a late acting form of $\mathrm{T}$ cell help other than IL-4 is required for IgE but not for IgG1 production. J. Immunol. 142:403408.

21. Geha, R. S., D. Y. M. Leung, D. B. Lewis, J. Abrams, H. H. Jabara, and D. Vercelli. 1989. Lymphokine profile in hyper-IgE syndrome. J. Allergy Clin. Immunol. 83:299 (511).

22. Chilson, O. P., and A. E. Kelly-Chilson. 1989. Mitogenic lectins bind to the antigen receptor on human lymphocytes. Eur. J. Immunol. 19:389-396.

23. Nishizuka, $Y .1984$. The role of protein kinase $C$ in cell surface signal transduction and tumour promotion. Nature (Lond.). 308:693698.

24. Yokota, A., H. Kikutani, T. Tanaka, R. Sato, E. L. Barsumian, M. Suemura, and T. Kishimoto. 1988. Two species of human Fce receptor II (FceRII/CD23): tissue specific and interleukin 4-specific regulation of the gene expression. Cell. 55:611-618.

25. Saryan, J. A., D. Y. M. Leung, and R. S. Geha. 1983. Induction of human IgE synthesis by a factor derived from $\mathrm{T}$ cells of patients with hyper-IgE states. J. Immunol. 130:242-247.

26. Saito, H., K. Hatake, A. Dvorak, K. Leiferman, A. Donnenberg, N. Arai, K. Ishizaka, and T. Ishizaka. 1988. Selective differentiation and proliferation of hematopoietic cells induced by recombinant human interleukins. Proc. Natl. Acad. Sci. USA. 85:2288-2292.

27. Plaut, M., J. H. Pierce, C. J. Watson, J. Hanley-Hyde, R. P. Nordan, and W. E. Paul. 1989. Mast cell lines produce lymphokines in response to cross-linkage of $\mathrm{Fc} \in \mathrm{RI}$ or to calcium ionophores. Nature (Lond.). 339:64-67.

28. Thyphronitis, G., G. C. Tsokos, C. H. June, A. D. Levine, and F. D. Finkelman. 1989. IgE secretion by Epstein-Barr virus-infected purified human B lymphocytes is stimulated by interleukin 4 and suppressed by interferon $\gamma$. Proc. Natl. Acad. Sci. USA. 86:5580-5584. 